\title{
La ciudad en la encrucijada neoliberal. Urbanismo mercado-céntrico y desigualdad socio-espacial en América Latina
}

\author{
The city in the neoliberal crossroads. Urbanism market- \\ centric and socio-spatial inequality in Latin America
}

\author{
A cidade na encruzilhada neoliberal. Urbanismo mercado- \\ cêntrico e desigualdade sócio-espacial na América Latina
}

Walter Fernando Brites

Instituto de Estudios Sociales y Humanos (IESyH-CONICET), Universidad Nacional de Misiones, Argentina.

\section{Resumen}

\begin{abstract}
A la luz de los aportes de numerosos investigadores, me propongo debatir en este artículo, lo que en auge se viene denominando como la ciudad neoliberal. Una ciudad remozada y remodelada, pensada y rediseñada por y para el mercado, donde los proyectos estratégicos como pensamiento único, redefinen el sentido de lo urbano. Los cambios en los procesos sociales, políticos, y económicos quedan objetivados en el espacio, acompañado por un pragmatismo arquitectónico que produce y recrea nuevas materialidades urbanísticas, residenciales, comerciales, de ocio con carácter más clasista. Argumento que la legislación reglamenta y divide, el mercado inmobiliario especula e interviene, los sectores carenciados son desplazados, y la inversión y des-inversión se materializan en ámbitos socio-espaciales diferenciados. La ciudad se re-estructura y la vieja forma espacial es aniquilada al emprenderse fuertes proyectos de re-inversión en espacios considerados deteriorados. Entornos urbanos embellecidos, paisajísticos, modernos, altamente equipados, creativos, etc., pasan a consolidarse como la cara visible de la ciudad, y fijan preceptos estéticos que legitiman y camuflan la desigual acción del urbanismo neoliberal.
\end{abstract}

Palabras clave: Mercado inmobiliario. Urbanismo. Desplazamiento. Clase social.

\begin{abstract}
In light of the contributions of many researchers, I propose to discuss in this article, what has been booming termed as the neoliberal city. A revamped and remodeled city, thought and redesigned by and for the market, where strategic projects as single thought, redefine the meaning of the urban. The political, economic and socials changes, are objectified in the space, accompanied by an architectural pragmatism that produces and
\end{abstract}

WFB es Dr. en Antropología e Investigador del CONICET, Argentina. e-mail briteswalter@yahoo.com.ar 
re-creates new urban materialities, residential, commercial, leisure, of more class character. I argue that the legislation regulates and divides, the real estate market speculates and intervenes, the disadvantaged sectors are displaced, and the investment and disinvestment are concretize in different socio-spatial areas. The city is restructured and the old spatial form is annihilated when undertaking strong re-investment projects in areas considered impaired. Urban environments beautified, of landscape views, modern, highly equipped, creative, etc., became consolidated as the visible face of the city, and establish aesthetic precepts that camouflages and legitimizes the unequal action of neoliberal urbanism.

Keywords: Real-estate market. Town planning. Displacement. Social class.

\section{Resumo}

À luz das contribuições de muitos pesquisadores, me proponho discutir neste artigo, o que cada vez mais vem sendo chamado como a cidade neoliberal. Uma cidade renovada e remodelada, pensada e redesenhada pelo e para o mercado, onde os projetos estratégicos como pensamento único, redefinem o sentido do urbano. As mudanças nos processos sociais, políticos e econômicos ficam objetivados no espaço, acompanhado por um pragmatismo arquitetônico que produz e recreia novas materialidades urbanísticas, residenciais, comerciais, de lazer com caráter mais classista. Argumento que a legislação regulamenta e divide, o mercado imobiliário especula e intervêm, os setores menos favorecidos são deslocados, e o investimento e o desinvestimento materializam-se em áreas sócio-espaciais bem diferenciadas. A cidade reestrutura-se e a velha forma espacial é aniquilada ao se empreender fortes projetos de reinvestimento nos espaços considerados deteriorados. Ambientes urbanos embelezados, modernos, criativos, panorâmicos, altamente equipados, etc., consolidam-se como o rosto visível da cidade, e fixam preceitos estéticos que camuflam e legitimam a ação desigual do urbanismo neoliberal.

Palavras-chave: Mercado imobiliário. Urbanismo. Deslocamento. Classe social.

\section{Introducción}

Desde la década de 1990 en adelante, las ciudades latinoamericanas han sido objeto de políticas urbanas que se han caracterizado por: a) la inversión selectiva de obras públicas en áreas urbanas; b) la implementación de nuevas legislaciones de ordenamiento y renovación urbana; c) la generación de entornos urbanos "embellecidos" y la promoción de competitividad turística; d) el facilitamiento al mercado inmobiliario para emprendimientos residenciales, comerciales, etc., e) la implementación de políticas habitacionales en áreas de apertura urbana o periféricas.

Progresivamente el conjunto de estas acciones han encontrado correspondencia con el proyecto global que expresa modelo neoliberal: la desigualdad (social, económica, habitacional, residencial, de acceso a infraestructura y oportunidades etc.).
Concretamente las ciudades han generado y/o consolidado nuevas centralidades urbanas, fragmentando el espacio urbano en su conjunto. Así, el fenómeno de la gentrificación, la periferización y la segregación socio-espacial emergen hoy de modo más notorio y marcado.

En un intento por conceptualizar y comprender dimensiones de esta problemática, en las páginas que siguen se presenta, de forma resumida, los aportes de autores en su mayoría latinoamericanos, que han sistematizado las experiencias urbanas de varias ciudades. Abundan en la literatura académica descripciones de nuevas regularidades espaciales observadas empíricamente, donde la planificación y la reorganización del suelo urbano ha aumentando la disparidad de la calidad del espacio residencial entre ricos y pobres.

Como se podrá observar, el urbanismo neoliberal instala una lógica de mercado, de costo-beneficio en la intervención y realiza un ajuste en la 
planificación urbana, ajustándolo a los intereses y funcionalidades de la especulación inmobiliaria del capital privado. Como punto de inflexión, la ciudad neoliberal se caracteriza por promover acciones gubernamentales concomitantes con el mercado. La entrada en escena del mercado torna más crítica la accesibilidad al espacio urbano, construye entornos residenciales embellecidos, clasistas (elitistas) generalmente favorecidos por proyectos de rehabilitación y renovación urbana y, en paralelo la ciudad reproduce estructuras urbanas muy precarias, proceso que ahonda la distancia entre clases en la ciudad.

\section{La emergencia del mercado y la ciudad neoliberal}

El decaimiento a nivel global del fordismo urbano, (estatal, regulador, modernista, etc.), generó una tendencia a la flexibilización urbana, conjuntamente con un desfinanciamiento estatal en infraestructura y políticas públicas, resurgiendo así el mercado como mecanismo de coordinación de la producción de ciudad (Abramo, 2011). Las problemáticas socio-espaciales y urbanas persistentes en las ciudades, que las normas urbanísticas de la modernidad trató de legislarlas, basadas en políticas regulacionistas de planificación y ordenamiento, hoy se reconfiguran y profundizan al unísono de nuevas políticas urbanas que re-estructuran la intervención estatal en la ciudad. La noción de integralidad del desarrollismo decayó, contexto donde el plan estratégico pasó a tener más importancia que el plan maestro, profundizado cambios y alteraciones de los sistemas urbanos de muchas ciudades.

Como antecedente a este planteamiento puede sostenerse que, el quiebre y agotamiento de una "matriz sociopolítica estado-céntrica" (Cavarozzi, 1997) y la implementación de una matriz mercadocéntrica neoliberal, reasignó al mercado libertad de acción (García Delgado, 1996; Oszlak, 2013; Brites, 2007). Así, de acuerdo a la lógica del paradigma neoliberal del Estado mínimo que reduce sus roles, tanto de regulador como de proveedor de bienes y servicios, es que sostengo que la planificación urbana se torna mercado-céntrica, usando excepcionalmente esta expresión en el campo del urbanismo.

Las secuelas del modelo neoliberal de profundización en la década de los 90's, como lo han descrito varios autores (Borón, 2000; Anderson, 1999; Petras, 2000), han sido múltiples en la región: desempleo, desigualdad social, pobreza, estallidos sociales, alzamientos, etc. A su fracaso le siguió el resurgimiento de la centralidad del Estado y el reflote de nuevos modelos de acumulación. No obstante, como señalan Tikell \& Peck (2002) el modelo neoliberal posee una capacidad de mutación, movilizando y extendiendo al mercado ${ }^{1}$. Aquí es que planteo que los valores de mercado dejan su impronta en el urbanismo neoliberal, generando nuevas materialidades urbanas (residenciales, inmobiliarias etc.), inclinadas más al consumidor que al ciudadano, de manera simultánea a la estructuración de un nuevo orden socio-espacial.

Siguiendo a las ideas de Smith (2009), quien sostiene que la función y la situación de las ciudades se vio cambiada de manera significativa durante la fase neoliberal del capitalismo, otros autores como Brenner \& Theodore (2004) señalan que la emergencia del urbanismo neoliberal encuentra su origen en las necesidades y demandas del modelo neoliberal, de legislaciones y políticas que favorezcan su desarrollo. Pradilla (2014), por su parte manifiesta que las ciudades latinoamericanas han sufrido cambios multidimensionales: "el cambio de patrón de acumulación de capital, del intervencionista estatal al neoliberal, han modificado la arquitectura del capitalismo y su territorio, acentuando sus rasgos y contradicciones y generando nuevos conflictos socio-territoriales" (Pradilla, 2014, p. 40). Hoy resulta llamativo, que a pesar de las características específicas de cada ciudad y de la orientación política de sus gobiernos, las mismas políticas urbanas (sus planes y proyectos) se vienen reproduciendo de forma creciente en distintas ciudades latinoamericanas (Delgadillo, 2014a).

A pesar de que la ciudad es el resultado de una conjunción de procesos desde lo que hace su propia población, hasta la intervención del mercado y del Estado en diferentes niveles. No obstante, las ciudades están expresando manifestaciones generales y propias del modelo de acumulación capitalista,

\footnotetext{
Básicamente la propuesta de estos autores, llaman la atención sobre los cambios históricos del proyecto neoliberal, así al margen de las características genéricas el neoliberalismo tiene un carácter variado donde es necesario tener presente las peculiaridades locales, las formas de regulación estatal, los patrones de resistencia, etc.
} 
cuyos efectos se despliegan a escala mundial. Así, desde la escala local hasta la global aparecen estrategias de desarrollo y revitalización urbana más visible y omnipresente (Swyngedouw, et al., 2004). La ciudad presenta un panorama en que la inversión en obras públicas y los programas de intervención no llegan a todos, son focalizadas, selectivas y excluyentes (acupuntura urbana), embellecen y revalorizan áreas haciendo más rentable la inversión privada (propiedades) allí localizadas.

Como oportunamente lo ha señalado Harvey (2007), el reconstruir y reinventar áreas deterioradas para convertirlas entornos urbanos embellecidos, implica una selectiva inversión pública en infraestructura de manera que el Estado subsidia al capital, contribuyendo al restablecimiento del poder y los privilegios de clase, lo que deriva en una creciente desigualdad socio-espacial. En otras palabras, el neoliberalismo urbano no depende solo de la especulación del suelo, la inyección de capital y de estrategias de mercado, sino también de la intervención del Estado y sus políticas a fin de generar condiciones económicas para que inversionistas privados inviertan en zonas urbanas degradadas (Smith, 2002; Harvey, 2007).

En la última década, la legislación urbana ha acompañado la lógica del mercado inmobiliario, generando una mayor re-mercantilización del espacio urbano. Las relaciones entre "lo social y lo espacial" han quedado evidenciadas en nuevas y crecientes "distinciones" residenciales entre diferentes sectores sociales. Por ello quiero plantear tres ideas básicas: a-, el neoliberalismo ha ampliado la distancia entre ricos y pobres, generando una mayor diferenciación social; b-, esa diferenciación social deriva en una diferenciación espacial o territorial, en ciudades cada vez más divididas; y c-, ese nuevo ordenamiento encuentra sus fundamentos en inéditos programas de planificación, renovación urbana, gentrificación y expulsión de los pobres de las áreas revalorizadas, etc.

Es incuestionable que tanto el turismo como la recualificación urbanística están formando parte del engranaje del nuevo desarrollo urbano, que de manera reiterada viene afectando a barrios pobres ubicados en la centralidad de las ciudades o en sus proximidades. La recurrencia de proyectos urbanos híbridos destinados a actividades comerciales, recreativas y también residenciales para familias del alto poder adquisitivo terminan desplazando a los pobladores originales, muchas veces residentes de antaño, como la remodelación de centros históricos con fines turísticos y comerciales.

San Telmo en Buenos Aires, Lapa en Río de Janeiro, o el centro histórico de Salvador Bahía son, solo por citar, casos emblemáticos de esta recualificación y renovación urbana, donde la avanzada del urbanismo renovador, mejora la infraestructura, legisla e impone dispositivos de seguridad que tienen fuerza de exclusión de la población original y/o marginada.

Como veremos en el siguiente apartado, si bien la desigualdad socio-espacial es la naturaleza que expresa la ciudad y la segregación es un fenómeno pre-existente y constitutivo, no obstante, en el marco de la lógica neoliberal de producción del espacio urbano, la gentrificación y la segregación son dos proceso que emergen prácticamente en simultáneo, evidenciando una implicancia mutua.

\section{Acerca de la renovación urbana, la segregación y el efecto gentrificación}

En las ciudades latinoamericanas, los problemas de la segregación, y periferización son fenómenos de larga data, su constitución histórica estuvo ligado al crecimiento espontáneo y desordenado de la trama urbana, al desarrollo de la ilegalidad e informalidad de los asentamientos populares, a la pobreza y marginalidad, etc., junto a un mix de situaciones y peculiaridades que presenta cada ciudad. En cambio, en la última década, estos procesos socio-espaciales afloran con un carácter más específico, se desprenden de nuevas políticas e intervenciones urbanísticas, que son fragmentarias y sectoriales, como el embellecimiento selectivo, el modernismo autoritario, la renovación urbana, el desplazamiento, etc., que ejecuta reapropiaciones, usos del suelo y del espacio urbano. En otras palabras, la segregación, la gentrificación y la expulsión a la periferia se originan en legislaciones y políticas urbanas que producen nuevas objetivaciones territoriales.

Los proyectos urbanísticos de renovación se consolidan como diferentes a intervenciones de etapas anteriores, realizando reformas en la ciudad. En la experiencia latinoamericana, la 
renovación urbana ha adquirido diferentes matices, desde consistir en una mecanismo para la regulación y reducción de asentamientos irregulares, una política para la inversión de capital para la revalorización del suelo, una estrategia para el mejoramiento de la imagen urbana, hasta un incentivo de desarrollo comercial y turístico (Ugalde Monzalvo, 2012). No obstante, en todos los casos, la renovación urbana como proyecto y como efecto, da lugar a un urbanismo desigual que deja su impronta en las ciudades. La zonificación residencial moldea la distancia social entre clases emergiendo con auge dos fenómenos particulares: la segregación y la gentrificación.

El concepto de gentrificación de Glass $(1964)^{2}$, aunque emergido para el abordaje de la realidad anglosajona, guarda capacidad heurística en el análisis de los cambios y transformaciones que atraviesan las ciudades latinoamericanas. Desde una perspectiva aggiornada refiere a un proceso de sustitución social con movilidad residencial. Un fenómeno que hoy adquiere inusitada relevancia en las áreas sujetas a fuerte revalorización urbana. La inversión y el desplazamiento cambian el carácter social de una zona, así resulta llamativo y acertado el planteamiento de Neil Smith (2002) de que la gentrificación es más precisamente el retorno de capital a la ciudad que de personas.

A propósito de la gentrificación, la observación más general que se puede hacer, refiere a el cambio social en la ocupación del espacio. Diferentes casos estudiados de gentrificación aluden a la reocupación de importantes áreas urbanas por parte de las clases más pudientes, mediante la rehabilitación habitacional, la demanda residencial y presión inmobiliaria que desplaza progresivamente a los ocupantes originales hacia otras áreas más baratas. Conjuntamente a la rehabilitación de viviendas otros autores refieren a la composición urbanística, social y económica detrás del cambio espacial (Sassen, 1991). Al margen de la propia dinámica inmobiliaria otros casos evidencian formas peculiares de gentrificación, vinculada de forma directa a los efectos de las obras de infraestructura que

\footnotetext{
“Una vez que el proceso de gentrificación comienza en un distrito continua hasta que todos, o la mayor parte de sus habitantes originales de clase trabajadora son desplazados y todo el carácter social del distrito es cambiado" Glass (1964, p. 18).
}

realiza el Estado (Brites, 2014) . $^{3} 0$ también a procesos diferenciales de gentrificación sin desplazamiento social (Delgadillo, 2014b).

Queda claro que con el apogeo del urbanismo neoliberal el proceso de gentrificación no aparece como resultado del espontaneismo, sino de la renovación urbana, inversiones y emprendimientos especulativos. En este sentido, coincidiendo con Tickell \& Peck (2002) las políticas actúan neoliberalizando el espacio, es decir conforman una modalidad de producción neoliberal del espacio urbano.

La nueva complicidad público-estatal y privada quedan evidenciada detrás de fuertes intervenciones/operatorias (llamadas de desarrollo urbano), que promueven en una multiplicidad de problemas y procesos, en la medida en que facilitan el cambio y sustitución en algunos barrios pobres, dando vía libre a la inversión privada en estos espacios de la ciudad (Sandroni, 2006). Acción que en variadas áreas urbanas conlleva una lógica de privatización de lo público: suelo e inmuebles, plazas, parques, reservas naturales, vialidades, áreas recreativas, etc., incorporándolas a un profundo proceso de mercantilización de los elementos de la estructura urbana (Pradilla, 2014). De modo que, la concreción de estos proyectos urbanísticos generan nuevos espacios urbanos que son ofrecidos al mercado conjuntamente con ciertas valoraciones y acentuaciones ideológicas positivas sobre el cambio (Millán \& Brites, 2014). El auge de la planificación pro-mercado en las ciudades, a través de políticas de marketing urbano (city-branding, turificación, etc.) como estrategia para mejorar la economía urbana, demuestran la escasez de alternativas para proponer un urbanismo diferencial acorde a la especificidad de cada ciudad y su gente.

El paisaje urbano se ve transformado y la creciente homogeneización física y funcional, en múltiples áreas de muchas ciudades, se ha visto acompañada por un aumento de su fragmentación espacial interna (Díaz Orueta, 2007). De forma recurrente, las grandes intervenciones urbanas, encuentran su sustento en el "embellecimiento estratégico y el turismo” (Boito \& Espoz, 2014). Partes de las ciudades

\footnotetext{
${ }^{3}$ El caso de las ciudades de Posadas Argentina y de Encarnación Paraguay, evidencian que grandes proyectos de desarrollo promocionados por el Estado, son cruciales para luego entender la dinámica inmobiliaria y su repercusión en los procesos de gentrificación.
} 
se desarrollan como marcas orientadas al mercado, con el fin de generar plusvalías de selectivos entornos urbanos. Este urbanismo escenográfico de belleza y distinción (Amendola, 2000) no solo tiene funciones estéticas, sino que fragmenta a la ciudad y re-estructura su territorio. En muchas ciudades, como parte de acciones de renovación urbana, se rehabilitan los bordes costeros con operaciones de remodelación urbana con consecuencias negativas en términos de desplazamientos y equidad social en el espacio urbano (Talesnik \& Gutiérrez, 2002) 4 .

De la misma forma en que aparece el Estado con políticas segregacionistas de los pobres, también aparece el mercado que segrega en función de la capacidad adquisitiva del consumidor. Desde este punto de vista, la gentrificación constituye un mecanismo de auto-segregación símil a la lógica de búsqueda de homogeneidad social en un country o barrio cerrado.

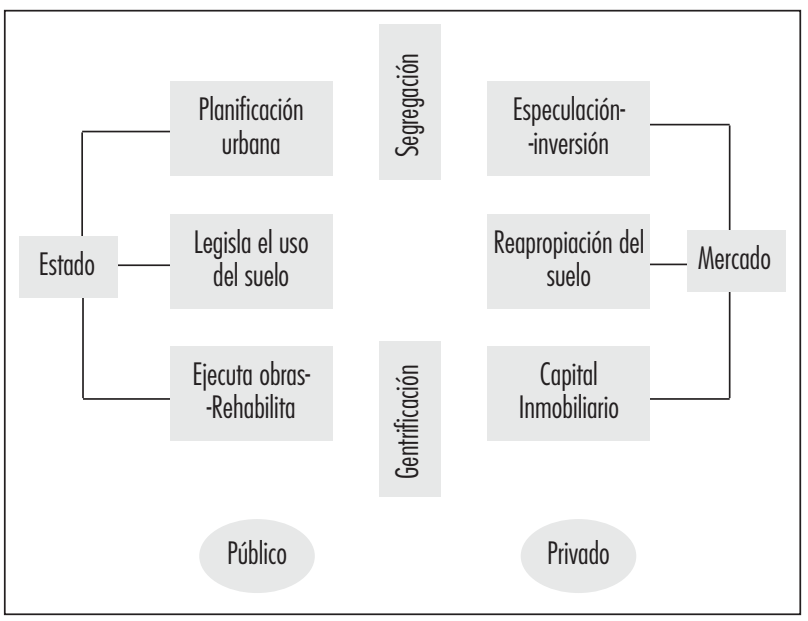

FIGURA 1 - Articulación Estado-Mercado en los procesos urbanos.

Fuente: elaboración propia.

Es crucial entender que la segregación genera un modelo de ciudad donde la distancia física, de alguna manera conlleva repercusiones en la distancia social (Brites, 2014). De modo que las relaciones entre las clases y sectores sociales se ve afectada: sin contacto social, no hay contrato social (Blakely \& Snyder, 1997). Estas situaciones conllevan limitaciones y adversidades para la vida cotidiana de los sectores más deprimidos y sus oportunidades de

\footnotetext{
4 Estos autores analizan los casos de Baltimore, Sidney, Barcelona y Buenos Aires que desarrollaron grandes intervenciones urbanísticas en el borde costero.
}

inserción en el mercado de trabajo urbano. A pesar de que estas situaciones constituyen un riesgo para el derecho al espacio urbano de los sectores populares, los desplazamientos son un epifenómeno de las políticas de renovación urbana.

Hoy muchas ciudades latinoamericanas evidencian que estas estrategias urbanísticas de variadas escalas, posibilitan una reapropiación del suelo por propietarios y corporaciones privadas. En Panamá desde hace unos 20 años, la renovación urbana de la ciudad de Panamá, desarrolla los conceptos de metrópoli moderna con intervenciones urbanísticas de vanguardia en la franja marítima y portuaria. El crecimiento de la ciudad tomó una forma lineal acorde a su ubicación costera sobre el pacífico. En su extensión la ciudad duplicó la altura promedio de los edificios, sobresaliendo las altas torres vidriadas que fueron ganando espacio a las viejas edificaciones y desplazando a pobladores y sus actividades. El estallido inmobiliario ha afectado muchas áreas, como el casco antiguo y la vida cotidiana de los pobladores de San Felipe y Santa Ana que hoy mal venden sus propiedades a inversores. Las barriadas, en tanto se extienden en dirección al aeropuerto, donde se multiplica la construcción de viviendas para hogares de bajos ingresos. En la costa caribeña de Panamá, la pequeña ciudad de Colón, por citar otro caso, aprovecha los corredores turísticos y su condición de zona libre comercial, para transformarse y revitalizar sus áreas urbanas. En 2015 se inició el proyecto de renovación urbana de la ciudad, que comprende la recuperación de espacios verdes, avenidas del Casco Antiguo de Colón y de edificios con valor histórico.

Desde la década de 1990 la Comuna de Santiago y la Corporación para el Desarrollo de Santiago (CORDESAN) han canalizado subsidios estatales de renovación urbana, promoviendo un mayor repoblamiento del centro (y de su área sur) a partir de la construcción de nuevos edificios de departamentos de alta rentabilidad, posesionándose en la ciudad que lidera el potencial inmobiliario de la renovación urbana residencial en Chile. Un contexto donde el sector inmobiliario de renovación urbana ha sido extremadamente expansivo mediante la producción de unidades habitacionales en torres elevadas, en diversos sectores del peri-centro (López-Morales, 2012). Esas edificaciones en altura que históricamente estuvieron en el centro de la ciudad han 
comenzado insertarse en barrios de viviendas unifamiliares provistas de patios arborizados, lo que modificado la vida de vecindarios (Ekdahl, 2011).

En muchas zonas de Santiago, los programas de renovación urbana de los últimos años, han evidenciado su articulación con la dinámica inmobiliaria, que han afectado no solo a su centro histórico, sino a barrios como: Lastarria, Yungay, Brasil, Bellavista, Santa Isabel, Italia etc., donde el tejido social y residencial de estos barrios se están fisurando como consecuencia de los efectos gentrificadores. Vecindarios comienzan a recibir no solo a residentes de mayor nivel socio-económico, sino ofertas de bienes y servicios como pubs, restaurantes, paseos, galerías de arte etc., dando una impronta bohemia a algunos de estos barrios. Más recientemente, en 2013 con el propósito es hacer compatible la vitalidad propia de un centro metropolitano con su potencial de desarrollo económico, social y cultural, la municipalidad y la CORDESAN han delineado acciones especiales, como el Plan Capital que propone un plan estratégico para el desarrollo turístico de Santiago, orientado a la modernización y mejora de la oferta turística.

En Bogotá se encuentra en marcha desde hace varios años, más de 20 planes de renovación urbana que buscan revitalizar áreas y re-estructurar usos del suelo, con variados efectos urbanísticos y sociales, como la remoción de barrios, el desplazamiento y la revalorización. Muchas de estas acciones se encuentran enmarcadas en el Plan Centro que busca la transformación económica, urbanística y social del centro de Bogotá a través de programas y proyectos de una coalición público y privada (la Alcaldía, la Secretaria del Hábitat, la Empresa de Renovación Urbana, Desarrolladores, Empresas constructoras, etc.). La transformación económica y residencial que se propugna ha disparado en alza especulación inmobiliaria que se encuentra afectando a muchos barrios tradicionales como: Las Cruces, Santa Bárbara, Alameda y Santa Fé. Mientras los inversionistas privados proyectan construir unidades de viviendas en apartamentos, oficinas y comercios, los desarrolladores ha realizado campañas de comunicación y reuniones con los vecinos y propietarios residentes en las áreas de renovación a fin de vincularlos a los proyectos, ya sea como socios, o bien mediante la venta sus inmuebles basado en los valores propuestos por las empresas inmobiliarias.
El argumento es que el centro es un lugar estratégico, no explotado, siendo necesario rehabilitar zonas poco aprovechadas o en desuso para convertirlas en una oportunidad para mejorar las condiciones económicas y sociales de sus residentes.

En el marco de estas acciones, actualmente esta en desarrollo el plan de renovación y revitalización urbana más ambicioso del centro de la ciudad: el Mega Proyecto Estación Central a cargo de la Empresa de Renovación Urbana (ERU) que ejecuta la construcción de una estación para el sistema integrado de transporte, además de altas torres de apartamentos en el predio y gestiona incluso el uso del suelo en el área. Además de obra pública el proyecto fue presentado como un complejo inmobiliario multidimensional, con impacto en la explotación comercial y la revitalización residencial ${ }^{5}$.

Básicamente el proyecto consiste en la renovación de más de 10 hectáreas en proximidad al sector financiero, con zonas especiales de viviendas, comercios, oficinas, universidad, servicios y espacios públicos. La peculiaridad de este proyecto, es la combinación del sistema de transporte con infraestructura inmobiliaria en el área cultural y comercial más neurálgica de Bogotá.

En Buenos Aires, en la década de 1990 surge la Corporación Puerto Madero S.A de administración fiduciaria, que se encargó de llevar a cabo el proyecto de Puerto Madero proponiendo desarrollar políticas dirigidas a rescatar el centro urbano de la ciudad de Buenos Aires. 20 años más tarde el desarrollo modernista y vanguardista de su intervención dejaría una marca en el entorno urbano de la cuidad a partir del rediseño de la vieja y abandonada zona portuaria de Buenos Aires. Los añejos edificios de ladrillos (fachada preservada, restaurada e interior reciclado), fueron reconvertidos en universidad, restaurantes, tiendas, etc., y en paralelo la construcción de altísimas torres vidriadas, promovidas por desarrolladores e inmobiliarias fueron cambiando el paisaje del área. Algunos estudios sobre el caso Puerto Madero, ponen énfasis en que detrás de la gestión de este de mega-proyecto urbano hay diversas estrategias empresariales de promoción de espacios competitivos para el capital inmobiliario

\footnotetext{
5 La estructuración económica hecha por la Compañía de Consultoría, Inversiones y Proyectos - CIP, bajo la dirección de la Empresa de Renovación Urbana (ERU) de Bogotá y TransMilenio S.A.
} 
(Cuenya \& Corral, 2011). Como en otras grandes intervenciones urbanas Latinoamericanas, Puerto Madero promovió espacios públicos de singular calidad, atractivo turístico y políticas activas para el desarrollo de la actividad inmobiliaria.

En Río de Janeiro, la renovación urbana y la gentrificación son un fenómeno en auge. Hacia el año 2000 en el centro carioca, la plaza Tiradentes y sus alrededores, un área vista como degradada y abandonada fue escogida para variadas intervenciones urbanas. La inversión pública atrajo al comercio sofisticado y a la especulación inmobiliaria, que dio lugar a redes de hoteles, bares y restaurantes, así como a estéticos edificios remodelados. Ese espacio urbano se redefinió como un centro de ocio y cultura para un público más elitizado siguiendo las mismas convenciones estéticas que la renovada zona de Lapa (Berocan Veiga, 2014).

Las acciones de intervención urbana no se limitaron al centro de la ciudad, sino a zonas costeras para incluirlas a un circuito de áreas revitalizadas para acompañar un proceso de cambio socio-urbano más amplio. Así, las acciones de recuperación del waterfront propuestas por el sector empresarial y el municipio se tradujeron en el "Plan de Recuperación y Revitalización del Área Portuaria de Rio", marco en el que se han desarrollado varios proyectos entre ellos: Porto Maravilha, de cara a las olimpiadas 2016, un proyecto de renovación urbana, que combina espacio público innovador, patrimonio y comercio. Aunque supera en escala a Puerto Madero (Buenos Aires), el proyecto carioca tiene algunas similitudes y diferencias. La intervención se desarrolla sobre un área mayor (500 hectáreas) de zonas definidas como degradas (barrios Gamboa, Santo Cristo y Saúde, morros de Pinto, Conceição, Providência y Livramento y, zonas de São Cristóvão, Cajú, Cidade Nova y Centro). Mientras en esta área residen miles de personas, Puerto Madero se encontraba vacío y abandonado. No obstante, ambos proyectos han generado cambios en el entorno urbanístico, arquitectura vanguardista y revalorización del suelo, con desplazamiento y/o llegada de nuevos residentes.

En la ciudad de Montevideo se observa la revitalización de áreas cercanas al puerto y al barrio Ciudad Vieja con incipientes evidencias del procesos de gentrificación (Abin Gayoso, 2014). En simultáneo a estos procesos en la ciudad esta en ejecución el Plan Estratégico Montevideo 2030 (MVD 2030), con destacadas acciones de renovación urbana, como el Proyecto de Acceso Norte, que platea recuperar áreas en proceso de vaciamiento y próximas a la bahía de Montevideo, estableciendo el vínculo entre ciudad y frente costero. La inversión en infraestructura y la re-estructuración de espacios públicos (jardines), esta siendo acompañada de nuevos y acondicionados edificios confortables para sectores de mayor poder adquisitivo.

Hacía el año 1996 en el centro histórico de Lima, gradualmente se han fomentados diferentes acciones de rehabilitación y recuperación de espacios a través de políticas que han promovido la remodelación de plazas, apertura de calles a peatones, desalojo de vendedores ambulantes, restauración de fachadas de monumentos, etc. Esta acción se profundizó con el Plan Estratégico 20062035 con el objetivo fue mejorar la infraestructura para la inversión privada, (comercial y turística). La llegada de capitales no tardaron en aparecer: cadenas de restaurantes, hoteles, reutilización y/o construcción de edificios públicos, y de edificios privados con oficinas boutique destinados a profesionales independientes, empresas inmobiliarias, etc., lo que significo cambios en la imagen urbana, el retorno de la inversión privada y de una nueva oferta orientada a niveles socioeconómicos más altos (Castillo Gómez, 2015).

Por otro lado, en varias zonas de Lima se están dando de la mano de la inversión privada y pública, incipientes y particulares procesos de gentrificación, como en el área de Monserrate y Barrios Altos donde de manera progresiva se están radicando sectores medios, medio-alto, en detrimento de la población de menor poder adquisitivo. Al sur de Lima el exclusivo distrito residencial de Miraflores esta re-desarrollando procesos de gentrificación en el corredor de La Mar donde la presión inmobiliaria ha ido vaciando su esencia para sustituirlas con apartamentos de lujo, nuevos comercios, cafés y restaurantes destinados al turista o al paseante. En muchos casos, el costo de vida se ha vuelto desorbitante y sus habitantes originales no lo pueden costear.

A nivel de la ciudad, en los últimos años han entrado en ejecución variados proyectos de rehabilitación a través del Fondo Municipal de Renovación Urbana (Fomur) orientado a mejorar áreas clave 
de la comuna metropolitana, concretando la remodelación integral de algunas áreas de la ciudad, como en la zona de Santa Clara de Barrios Altos (Programa de Recuperación de Barrios Altos), que mejora el mobiliario urbano. Otro caso, por citar, es el Circuito Mágico del Agua que promociona circuitos y servicios turísticos, comerciales y gastronómicos en un nuevo entorno elegante, que ha revalorizado el área circundante. Estas situaciones se manifiestan en simultáneo a la emergencia y construcción de barrios populares en contextos de segregación residencial, con problemas de servicios, dificultades de transporte público y con escasa vinculación al espacio urbano.

De modo general, debe destacarse que la renovación urbana y el desplazamiento no son fenómenos exclusivos de las metrópolis latinoamericanas, sino también de las ciudades de tamaño medio, independientemente de su longevidad. Ciudades nuevas y viejas, con y sin centro histórico se "renuevan", se re-diseñan de a fragmentos, se re-inventan y se promocionan en el mercado. Aunque son numerosos y crecientes los casos de transformación en las ciudades medias, no lo desarrollamos aquí por falta de espacio. Las lógicas del urbanismo neoliberal están allí plasmadas: el cambio en la normativa, la inversión del capital privado inmobiliario, intervención del mega sector de la construcción, revalorización del suelo urbano y desplazamientos.

\section{Suelo urbano, desarrolladores y mercado inmobiliario}

No es mi intención hablar aquí sobre las regulaciones del uso de la tierra, sino más bien centrarme en los aspectos comunes que la revalorización y la especulación inmobiliaria generan sobre la expansión urbana. Hoy el discurso de la flexibilización urbanística es acompañado de una presunta eficacia del mercado del suelo urbano e inmobiliario en la producción de la estructura urbana (Abramo, 2011). Aunque ya décadas atrás Topalov señalara que en la lógica de urbanización capitalista concurren una "multitud de procesos privados de apropiación de espacio" (Topalov, 1979, p. 20), no obstante, la entrada en escena de la especulación inmobiliaria en la economía urbana neoliberal es mucho más compleja.

Es merecidamente importante señalar que en el nuevo proceso de valorización del suelo urbano interviene una alianza público-privada: el Estado y sus políticas de intervención urbana y, el mercado a través de sus instituciones financieras/inmobiliarias que estimulan la inversión en áreas de creciente especulación urbana. El Estado de alguna manera juega un papel importante. Tanto la obra pública como los programas de rehabilitación, dinamizan y complejizan el juego de lo público y lo privado en su actuar sobre la ciudad. Así, una obra de pavimento, la construcción de una plaza o espacio de ocio, incide en el crecimiento de una zona, revalorizando espacios, suelos, (lotes) que luego, vía mercado, se apropian los sectores de mayor poder adquisitivo.

La entrada en escena de los denominados desarrolladores inmobiliarios emergen en paralelo a grandes obras públicas que afectan en muchas ocasiones a barrios pobres y asentamientos informales, que van quedando en intersticios claves del suelo urbano valorizado. La oferta de edificios con vistas panorámicas, con proximidades a externalidades urbanas de calidad, etc., no solo valoriza el suelo, sino que ejerce presión de mercado sobre los lotes disponibles. Contexto en donde la especulación inmobiliaria es orientada por los intereses de actores de poder económico y político.

Retomando a Harvey, (2008) las ideas de destrucción creativa ${ }^{6}$ y de acumulación por desposesión, son aplicables a las operatorias de recualificación urbana, de cambios en los perfiles de la ciudad, de reinvención y revalorización funcional al capital inmobiliario y a la atracción de inversiones. A nivel de la ciudad, la lógica de la acumulación del capital se plasma en formas espaciales específicas, que sin embargo, su necesidad de expansión tiende a destruirla (ampliando escalas, renovando infraestructuras, etc.). La competitividad exige cambio mediante destrucción y creación, así los espacios urbanos son seccionados en diferentes entornos singulares (comerciales, paisajísticos, recreativos, residenciales, etc.), y ofrecidos al mercado. La acumulación por desposesión en tanto refiere a un

\footnotetext{
6 Idea retomada del economista marxista Joseph Schumpeter (1976), quien caracterizó al capitalismo como "un proceso de destrucción creativa".
} 
proceso de desplazamiento, de fuerzas mercantilizadoras y privatizadoras que determinan la pérdida de un espacio. La desposesión y la destrucción tienen una dimensión de clase, en la medida en que la re-estructuración urbana genera violencia sobre los pobres consolidado las desigualdades socio-urbanas.

La inversión pública en infraestructura y dotaciones urbanas viene generado un aumento vertiginoso del precio del suelo urbano, haciéndolo accesible a los sectores de mayor poder adquisitivo $\mathrm{y}$, en paralelo los sectores populares se ven obligados a ocupar espacios residuales en áreas alejadas o periurbanas. De hecho Sabatini (2005) evidencia que para el caso de Chile, este proceso empujó la construcción de nuevos conjuntos habitacionales hacia lugares mucho más alejados de los centros urbanos. Un fenómeno hoy muy típico en muchas metrópolis y ciudades medias latinoamericanas. Lungo (2011) señala efectos negativos de esta forma de expansión urbana con altos costos, en términos de problemas de acceso a los servicios urbanos, la calidad de vida y la segregación socio-espacial. En este sentido, Abramo (2012, p. 39) sostiene: "el retorno - o la reafirmación - del mercado de suelo se constituye en una fuerza que potencia la producción de una estructura socio-espacial desigual".

Las políticas de revalorización urbana y consecuentemente de especulación sobre el suelo urbano, están modificando los patrones de organización y ocupación del espacio residencial. La multiplicidad de programas de rehabilitación, relocalización/remoción con igual contenido y características están transformando barrios enteros. Por un lado, la proliferación de mega proyectos ejecutados en los bordes costeros que regeneran frentes fluviales, y por otro, la implementación de políticas de viviendas sociales hacía áreas periurbanas en conjuntos habitacionales, están poniendo de relieve un paisaje urbano más homologado. De hecho, varios autores (Arancibia, 1995; Smith, 2009) sugieren que la expulsión de población pobre hacia lugares donde el suelo es más barato es una de las características de las políticas neoliberales.

La producción inmobiliaria causa un desmoronamiento del orden socio-espacial y de la planificación urbana tradicional. Las intervenciones del nuevo urbanismo, crea y aprovecha las estructuras de oportunidades generadas, en sinergia con la recualificación del suelo urbano, fundamentalmente en áreas de rehabilitación-regeneración. El contexto económico y socio-político en el que emerge la ciudad neoliberal, propicia y facilita la aparición de nuevos grupos empresariales dedicados a la cuestión urbana. Así, la legislación no solamente regula, trata de atraer inversores y obtener recursos para financiar la renovación urbana ${ }^{7}$. La figura de desarrolladores inmobiliarios, empresarios de la construcción, operadores turísticos, financistas, fideicomisos, y otras asociaciones empresarias habilitadas para actuar en el mercado comienzan a producir ciudad. El alquiler y/o venta de departamentos, oficinas, y otros locales para shopping o gastronomía, constituyen estrategias de inversión y rentabilidad que fijan tendencias importantes en el mercado inmobiliario.

En un contexto de incremento de los valores del suelo urbano, las concesiones que realiza la legislación urbana, (con su omisión y/o acción) al capital inmobiliario delinea una inclinación empresarial en la gestión del problema urbano. Así, a la acción de la intervención pública le siguen las reglas del libre mercado al aumentar la presión inmobiliaria por la compra de inmuebles con mayores rentas, por lo que el costo del suelo urbano tiende a subir como consecuencia del aumento de demanda. Por otro lado, es común la proliferación de políticas tributarias que elevan los impuestos en las áreas de renovación convirtiéndolas en zonas caras para la vida de los sectores populares que (cuando no son removidos), terminan por mal-vender sus propiedades.

El mercado del suelo urbano se presenta como diferencial y en ese orden la problemática de la segregación es transversal. Hoy el fenómeno de la segregación socio-espacial, está muy relacionado con lo que Jaramillo (2003) denomina la renta diferencial de vivienda (los grupos que buscan y habitan las mejores localización urbanas, muchas veces con proximidad a los mejores servicios pagan un sobreprecio por la vivienda), un fenómeno para Jaramillo también asociado a la renta por

\footnotetext{
7 En algunas ciudades brasileñas, a partir de una norma los desarrolladores, pueden comprar capacidad constructiva Certificados de Potencial Adicional Constructivos (CEPACs), al igual que una compra de bonos, habilita al propietario a incrementar la capacidad constructiva en un área determinada.
} 
monopolio de segregación, que refiere a una práctica de nucleamiento de los grupos de mayor poder adquisitivo en lugares de distinción de clase, separados, diferenciados y en ocasiones exclusivos y por ende su ingreso tiene un plus o sobre precio por los inmuebles.

Con el auge del mercado del suelo urbano, el urbanismo promueve y desarrolla nuevas objetivaciones urbanas y arquitectónicas de carácter clasista y privatista (los country, barrios cerrados, clubes náuticos, edificios con vistas panorámicas, espacios de seguridad, departamentos de confort, amenities, etc.), se materializan no solo como barreras físicas y económicas, sino también simbólicas y sociales. Estos espacios residenciales al constituirse como "exclusivos", son por tanto altamente selectivos y excluyentes. Un engranaje más en la polea de la fragmentación socio-territorial.

La intervención del mercado en las decisiones urbanísticas, no solo deriva en apropiaciones estratégicas y selectivas de los mejores espacios con fines de inversión privada, sino que su sinergia con la acción pública y la especulación inmobiliaria aumenta los costos y valores del suelo urbano y de las edificaciones existentes. Como efecto global en la ciudad se re-estructuran procesos urbanos, donde la aparición de gentrificación, la segregación y/o sub-urbanización dan lugar a la configuración de ciudades compactas y/o difusas (Tomadoni \& Knierbein 2009; Abramo, 2011). Las ciudades se contraen o compactan en las áreas centrales y/o bordes fluviales revalorizados y, se expanden hacia nuevas periferias donde la combinación de suelo disponible y barato orienta la construcción de viviendas sociales expandiendo el loteo y la mancha urbana.

Las necesidades habitacionales de los sectores medios y en ocasiones populares no están exentos a la lógica de mercado. Las empresas constructoras en complicidad con especulaciones inmobiliarias y financieras irrumpen en las políticas habitacionales incidiendo en la localización de los conjuntos de viviendas sociales y sus características. Multiplicadas son las experiencias en América Latina donde el costo del suelo es una variable de ajuste que orienta la localización de los conjuntos habitacionales, tanto los entes gubernamentales como las empresas constructoras, han optado por terrenos alejados, peri-urbanos, donde el costo del suelo es barato.

\section{Reflexiones finales: Ciudad desmembrada, ciudad re-ordenada}

El hilo argumentativo de este trabajo consistió en sostener que urbanismo neoliberal, realiza un ajuste en los patrones de ocupación del espacio urbano, ajustándolo a las lógicas y necesidades del mercado del suelo y del capital inmobiliario. Los nuevos programas de intervención, el rediseño arquitectónico del espacio, y las normas urbanísticas constituyen dispositivos materiales e ideológicos que regulan y re-estructuran a la ciudad, haciéndola más segmentada, poco integrada. El conjunto de estas intervenciones constituyen un punto de inflexión en la forma en que se replantean las ciudades.

Los megaproyectos revalorizan el suelo urbano, dando lugar a diversas formas de desplazamiento, desde el amedrentamiento legal y jurídico de los asentamientos informales (relocalización, remoción), hasta inéditas formas de desplazamiento vía elevación de los impuestos, presión inmobiliaria, cambios del entorno, pérdida de la identidad barrial, gentrificación, etc. La lógica del mercado des-ordena y re-ordena a la ciudad ubicando a cada quien en su lugar, el poder adquisitivo constituye así, la base para jerarquizar el derecho al espacio y al habitar.

La planificación estratégica sustituye a la planificación urbana tradicional, delineando una estrategias de mercado para la revalorización urbana. La competitividad, innovación, renovación, etc., propia de una visión empresarial, constituye una justificación para reorganizar el espacio y desplazar. Corrientemente estas acciones afectan al entorno de los barrios populares y de sectores medio-bajo, que quedan bajo presión del avance de obras públicas (programas de renovación) y de la especulación del mercado. De la mano de la renovación urbana, funcionarios, operadores turísticos, promotores inmobiliarios, desarrolladores, etc., traman la ciudad de acuerdo a los intereses y especulaciones del mercado inmobiliario.

Las políticas urbanas aliadas a la lógica de producción inmobiliaria, vía mercado, no solo generan nuevas materialidades urbanas sino que producen un cambio en el tejido social urbano, que se expresa en nuevos desplazamientos, diferencias, distancias y en la construcción de homogenidades. Esta nueva irrupción del mercado en la planificación, situa cada vez más a la ciudad en la encrucijada neoliberal. 


\section{Referencias}

Abin Gayoso, E. (2014). Por el derecho de los vecinos a vivir en su barrio. Revista TRAMA. Auas. (5). (p. 61-75).

Abramo, P. (2012). "La ciudad com-fusa: mercado y producción de la estructura urbana en las grandes metrópolis latinoamericanas". Revista Eure, 38(114), 35-69.

Abramo, P (2011). La producción de las ciudades Latinoamericanas: mercado inmobiliario y estructura urbana. Colección Textos urbanos. Quito. v. IX. OLACCHI.

Amendola, G. (2000). La ciudad posmoderna. Magia y miedo de la metrópolis contemporánea. Madrid: Celeste Ediciones.

Anderson, P. (1999) Neoliberalismo: balance provisorio. En E. Sadder \& P. Gentili (Compiladores). La Trama del neoliberalismo. Mercado, crisis y exclusion social. Buenos Aires: Clacso/eudeba.

Arancibia Martinez, L. (1995). El problema de los desalojos en la ciudad de México. La lucha de las organizaciones urbano populares por el derecho a vivir en la ciudad. México DF: Casa y Ciudad.

Berocan Veiga, F. (2014) "Los vientos que vienen de Lapa: la danza social y la plaza Tiradentes como escenario de las transformaciones urbanas en el centro Carioca”. En M. Millán \& W. Brites (Eds.). Ciudades Vivas. Imaginaciones sobre el territorio. (1. ed. p. 158-192). Posadas: Ed. Creativa.

Blakely, E. \& Snyder, M. (1997). Fortress America. Gated communities in the United States. Washington, DC: Brookings Institution Press-Lincoln Institute of Land Policy.

Boito, M. \& Espoz, B. (2014). "Vaciar la calle, prometer la circulación. Desplazamientos y construcción de entornos protegidos en el marco de las sociedades del espectáculo" En: M Boito. \& B Espoz (eds.) Urbanismo estratégico y separación clasista. Instantáneas de la ciudad en conflicto. Rosario: Ed. Puño y letra.

Borón, A. (2000). Tras el búho de Minerva: mercado contra democracia en el capitalismo de fin de siglo. Buenos Aires: CLACSO.

Brenner, N. \& Theodore N. (2004). Spaces of Neoliberalism. Urban Restructuring in North America and Western Europe. Oxford. (eds.): Blackwell.
Brites, W \& Millán, M. (2014). “Procesos urbanos: entre segregación, renovación y reinvención. En M. Millán \& W. Brites (Eds.). Ciudades Vivas. Imaginaciones sobre el territorio. (1. ed. p. 15-29). Posadas: Ed. Creativa.

Brites, W. (2009). Neoliberalismo, exclusión social y la deconstrucción de la ciudadanía (recurso electrónico) e-libro, Corp. El Cid Editor. apuntes. 18 p.

Brites, W. (2014). “La mega-hidroeléctrica Yacyretá en el vórtice de las reconfiguraciones urbanas. El caso de las ciudades de Posadas, Argentina y Encarnación, Paraguay". URBS. Revista de Estudios Urbanos y Ciencias Sociales, 4(2), p. 91-107.

Castillo Gómez, C. (2015) ¿Gentrificación a la limeña en el Centro Histórico de Lima? ¿Expulsión o inclusión? 19932013. En Delgadillo V. Díaz I. \& Salinas L. (Coordinadores) Perspectivas del estudios de la gentrificación en México y América Latina. p 133-152. Contested Cities-UNAM, México.

Cavarozzi, M. (1997) Autoritarismo y democracia (19551996). La transición del Estado al mercado en la Argentina. Buenos Aires: Ariel.

Cuenya, B. \& Corral, M. (2011). Empresarialismo, economía del suelo y grandes proyectos urbanos: el modelo de Puerto Madero en Buenos Aires. En revista EURE, 37(111), p. 25-45, Santiago.

Degadillo, V. (2014a). Urbanismo a la carta: teorías, políticas, programas y otras recetas urbanas para ciudades latinoamericanas. En Cadernos Metrópole. São Paulo, 16(31), p. 89-111. Recuperando de http://dx.doi. org/10.1590/2236-9996.2014-3104.

Degadillo V. (2014b), “¿Gentrificación sin desplazamiento social?" En Ciudades n. 103, p. 2- 8.

Díaz Orueta, F. (2007). Los grandes proyectos de desarrollo urbano y la reconfiguration socio-espacial de las ciudades: el barrio de Lavapiés (Madrid). En Cuaderno Urbano n. 6, p. 169-194.

Ekdahl, K (2011). Renovación urbana en el centro de Santiago: Dinámicas de barrio y procesos de transformación en microterritorios (Tesis). Facultad de Arquitectura y Urbanismo, Universidad de Chile, Chile.

García Delgado, D. (1997) La reforma del Estado en la Argentina: de la hiperinflación al desempleo estructural. Revista del CLAD Reforma y Democracia. (8) may. 1997. Caracas. 
Harvey, D. (2007). Urbanismo y desigualdad Social. Barcelona: Ed. Siglo XXI.

Harvey, D. (2008). "El derecho a la ciudad". En New Left Review (NLR) 53, p 23-39. Recuperado de http://newleftreview.es/53

Jaramillo, S. (2003). “Los fundamentos económicos de la participación en plusvalías". Documento preparado para el CIDE Universidad de los Andes y el Lincoln Institute of Land Policy. Inédito. Recuperado en 3 de mayo de 2014 de http://institutodeestudiosurbanos.info/dmdocuments/ cendocieu/

López-Morales, E. (2012). Urbanismo Empresarial y Destrucción Creativa. Un estudio del caso de la estrategia de renovación urbana en el pericentro de Santiago de Chile 1990-2005. Serie Investigación sobre vivienda en Iberoamérica. Infonavit-Redalyc. Santiago.

Lungo, M. (2011). Grandes proyectos urbanos: una visión general. En: M Lungo. América Latina países pequeños de grandes ciudades. Colección Textos Urbanos volumen X. OLACCHI. Quito.

Oszlak, O. (2013). La gestión pública post-NGP en América Latina: balance y desafíos pendientes. En: IX Jornada de la INPAE: Enseñanza y Pedagogía de la Gestión de Políticas Públicas: Desafíos y Actualidad para un Nuevo Servicio Público. Santiago, Chile, may.

Peck, J. \& Tickell, A. (2002). “Neoliberalizing Space”. En Antipode A radical journal of geography, 34(3), p. 380-404.

Petras, J. (2000). La izquierda contraataca. Conflicto de clases en América Latina en la era del neoliberalismo. Madrid: Akal.

Pradilla, Cobos E. (2014). La ciudad capitalista en el patrón neoliberal de acumulación en América Latina. En Cad. Metrop., São Paulo, 16(31), p. 37-60. Recuperado de http://dx.doi.org/10.1590/2236-9996.2014-3102

Sandroni, P. (2006). Renovación urbana y gentrificación: evaluación de algunos impactos demográficos, sociales y económicos de la operación urbana Faría Lima en la ciudad de San Pablo. Revista Medio Ambiente y Urbanización, 65(1), p.109-110.

Sassen, S. (1998). “Ciudades en la economía global: enfoques teóricos y metodológicos". Revista EURE, XXIV(71), p. 5-25, Santiago de Chile.
Smith, N. (2002). New globalism, new urbanism: Gentrification as global urban strategy, En Antipode, 34(3), p. 427-450.

Smith, N. (2009). “¿Ciudades después del neoliberalismo?" En VV.AA. Después del neoliberalismo: ciudades y caos sistémico, Barcelona: MACBA; UAB.

Swyngedouw, E. Moulaert F. \& Rodríguez, A. (2004). "Neoliberal Urbanization in Europe: Large-Scale Urban Development Projects and the New Urban Policy", en N Brenner \& N Theodore (eds.) Spaces of Neoliberalism. Urban Restructuring in North America and Western Europe. Oxford. Blackwell.

Talesnik, D. \& Gutiérrez, A. (2002). Transformaciones de frentes de agua: la forma urbana como producto estándar. Revista EURE 28(84), p. 21-31.

Tomadoni C. \& Knierbein S. (2009). La producción del espacio urbano en cambio. Gestión y Ambiente, 12(1). p 13-18.

Topalov, Ch. (1979). La urbanización capitalista. Algunos elementos para su análisis: México: Editora Edicol.

Ugalde Monzalvo, M. (2012). Renovación Urbana Sostenible. En: Memorias de ponencias Think Green 2012: Economía verde y desarrollo sostenible en México. p. 1-10. Ciudad de México: Instituto Global para la Sostenibilidad.

Sumisión: 19/09/2016 Received: $19^{\text {th }}$ September 2016 Aprobación: 01/11/2016 Approved: $01^{\text {st }}$ November 2016 


\section{Erratum}

En el artículo "La ciudad en la encrucijada neoliberal. Urbanismo mercado-céntrico y desigualdad socio-espacial en América Latina", con número de DOI: 10.1590/2175-3369.009.003.A014, publicado en el periódico urbe. Revista Brasileira de Gestão Urbana, 9(3), 573-586, sept./dic. 2017 (http://www.scielo.br/ scielo.php?script=sci_issuetoc\&pid=2175-336920170003\&lng=en\&nrm=iso):

Donde dice:

Walter Fernando Brites

Universidade Nacional Autónoma do México (UNaM), Cidade do México, Me.

WFB es Magíster en Políticas Sociales UNaM. Docente e investigador. Becario doctoral del CONICET. e-mail briteswalter@yahoo.com.ar

Debe ser leído:

Walter Fernando Brites

Instituto de Estudios Sociales y Humanos (IESyH-CONICET), Universidad Nacional de Misiones, Argentina. WFB es Dr. en Antropología e Investigador del CONICET, Argentina. e-mail briteswalter@yahoo.com.ar 